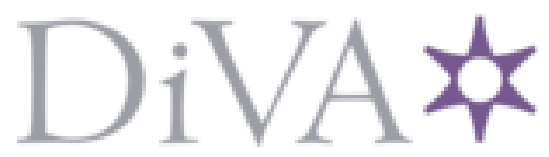

http://www.diva-portal.org

This is the published version of a paper published in Svensk skattetidning.

Citation for the original published paper (version of record):

Hultqvist, A. (2007)

En Tätningskommission i stället för genomsyn och skatteflyktslag.

Svensk skattetidning, : 229-235

Access to the published version may require subscription.

N.B. When citing this work, cite the original published paper.

Permanent link to this version:

http://urn.kb.se/resolve?urn=urn:nbn:se:su:diva-9603 1 


\title{
En Tätningskommission i stället för genomsyn och skatteflyktslag ${ }^{1}$
}

\author{
Av Anders Hultqvist
}

\section{Bakgrund}

I decennier har vi nu diskuterat problemet med s.k. luckor i skattelagstiftningen från ett rättstillämpningsperspektiv. Skatteflyktslagar, genomsynsresonemang, helhetssyn är svenska varianter av "substance over form" (USA), realekonomi (Danmark), "new approach" (Storbritannien), "gjennomsjaerning" (Norge), "Missbrauch" (Tyskland) osv. Ingenstans lyckas man finna en bra lösning på problemet utan kritiken bara flödar mot den ena efter den andra modell som prövas för att komma tillrätta med "lagstiftningsluckor".

Fenomenet uppmärksammades redan på 1930-talet, men fick en seriös behandling hos oss först under 1950-talet, framförallt genom Dag Helmers' avhandling om kringgående av skattelag 1956 och 1953 års Skatteflyktskommitté som lade fram sitt betänkande 1963. Båda kom fram till att det inte var möjligt att lösa problemet i rättstillämpningen, utan, som Helmers konstaterade i slutet i sin avhandling, att det är en "sorgfällig avfattning av skattelagen" som erfordras.

Saken var avgjord. Problemet fick lösas från ett lagstiftningsperspektiv, inte ett rättstillämpningsperspektiv.

\section{Rättstillämpningsperspektivet}

Förespråkarna för rättstillämpningsperspektivet gav sig inte. Under 1970-talet utreddes frågan på nytt och resulterade år 1980 i en "rättssäker" generalklausul, så rätts-

1. Vad som framförs i denna debattartikel är ett koncentrat av vad jag skrivit om i drygt ett decennium i denna fråga. Källor och argument finns redovisade i min avhandling, Legalitetsprincipen vid inkomstbeskattningen, 1995, kap. 7 och 8 och i artiklar i olika skattetidskrifter, senast i denna tidskrift 2005 s. 302 ff., till vilka den intresserade läsaren hänvisas.

SvSkT 4/2007 
säker att den inte tillämpades av Regeringsrätten. 1983 var det dags för en mer offensiv variant av skatteflyktslagen. Den fick sina anhängare men också sina motståndare. "Lagstiftningens grunder" skulle tillämpas när en ordinär tolkning av lagen inte räckte till. Om inte förarbetena gav något ytterligare normmaterial, fick man söka finna "lagstiftarens avsikt" - ett argument som redan under 1930-talet avslöjades som ett s.k. skenargument av dåtidens rättsfilosofer. En institution - lagstiftaren, riksdagen - kan inte ha en avsikt. Det kan endast människor ha. Eller som Lars Hjerner påpekade redan 1983: Lagstiftaren får väl antas kunna tala om vad han vill, dvs. det som inte framgår av lagstiftningen finns inte och ska definitivt inte beaktas om det inte kommit till uttryck i lagstiftningen.

Sanningen låg snarare i den tredje metoden enligt förarbetena, nämligen att skattelag skulle tillämpas analogt när så erfordrades. Problemet med en analog tillämpning är dock vad som är kriteriet för när så skall ske. Att domstolar får tillämpa detta skön på civilrättsområdet är inte ett tillräckligt argument, eftersom domstolarna i sådana fall har att utveckla rätten utifrån grundläggande civilrättsliga principer om avtalsbundenhet, skadestånd vid culpa osv. Där finns inte e contrario-möjligheten att säga att det inte finns någon norm för fallet (deni de justice-förbudet). På straff- och skatteområdet är det dock så - enligt legalitetsprincipen, särskilt med hänsyn till dess föreskriftskrav - att det inte bara är försvarbart utan t.o.m. det enda rimliga att konkludera att det inte finns något brott utan lag, respektive ingen skatt utan lag. En logisk konsekvens av föreskriftskravet är ett analogiförbud, vilket konstaterats i en rad rättsvetenskapliga avhandlingar. Skatteflyktslagen innebär således något som är förbjudet enligt grundlagen, där legalitetsprincipen har sitt stöd.

Med den föreslagna vägledningen i förarbetena till skatteflyktslagen - förarbetena till skattebestämmelserna, lagstiftarens avsikt och analogier - kan man inte komma till något annat än att godtycklig beskattning rekommenderas i vissa fall, där normen skapas av domstolen i det enskilda fallet och med retroaktiv verkan för den enskilde, vilket är i konflikt med grundlagen. Allt annat är en teoretisk omöjlighet.

Skatteflyktslagen avskaffades i början av 1990-talet, för att åter införas 1995. Under tiden växte sig "genomsynen" stark och har sedan hävdats parallellt med skatteflyktslagen efter återinförandet. En stor fördel för skatteförvaltningen var att "genomsyn" kunde tillämpas direkt vid taxeringen, i stället för att vara beroende av att talan väcktes hos länsrätten.

"Genomsynen" är dock varken en metod eller en rättsprincip, som den ibland påstås vara. Hade den varit en metod, skulle vi rimligen ha blivit presenterade en metodologi någon gång under alla dessa år. Den saknas fortfarande och det beror naturligtvis på att det inte finns någon sådan. En rättsprincip - t.ex. sådan som culpaprincipen inom skadeståndsrätten - har jag heller inte sett något spår av. "Genomsynen" är i stället det som den, för nordisk rätt, kände danske rättsvetenskapsmannen, Alf Ross kallade för ett "tu-tu-begrepp", med referens till en påhittad stam i Afrika, 
som kallade allt de inte kunde förklara för "tu-tu". Det finns exempel på domar, som kan vara uttryck för en mer fri beskattning, men det kan också vara något annat, bara att resonemanget inte framgår tydligt av domskälen eller att domskrivningen blev olycklig. Oavsett vilket alternativ som är det riktiga, finns det ingen dom som presenterar en hållbar teori om någon slags genomsyn. Det som är mer påtagligt, när man läser nutida underrättsdomar, är att de utgör ett slags osammanhängande rättsfallsmaterial, där man aldrig kan visa en röd tråd i resonemanget.

Den nya skatteflyktslagen skulle respektera legalitetsprincipen, var det tänkt. Därför skulle man i stället för "lagstiftningens grunder" (ett uttryck som brukar användas i analogisammanhang), se till "lagstiftningens syfte", som det framgår av lagstiftningen (skattebestämmelsernas allmänna utformning, de bestämmelser som är direkt tillämpliga eller som har kringgåtts).

Man skulle nu inte titta i förarbetena längre, utan direkt i föreskrifterna, och finna ett syfte som inte ingår i den normala, traditionella lagtolkningen. Först läser och tolkar man lagtexten, som vid all annan juridisk tolkning, och kommer till ett visst resultat. Detta resultat visar sig dock vara otillfredsställande. För genom den ordinära, traditionella lagtillämpningen, har den skattskyldige fått en förmån, en "skatteförmån", ett tankesätt jag inte ens begriper mig på. Då ska man, efter att ha konstaterat att den skattskyldige själv varit delaktig i att skaffa sig denna förmån och att det varit en väsentlig del i att förfarandet kommit till stånd, finna att det strider mot det "syfte" som nu ska kunna utläsas av enbart lagtexten.

Hur skall detta gå till? När jag först tolkade lagen, såg jag inte detta syfte, i vart fall inte på ett sådant sätt att det påverkade min tolkning. När jag sedan ser vad min tolkning lett till, att en "skatteförmån" uppkommit, tittar jag åter på lagtexten med mina andra glasögon, särskilt konstruerade för att se bakomliggande syften. Då framträder ett annat syfte, än vad jag ser när jag först tolkar lagen. Jag måste ärligt säga, att jag inte begriper hur det skall gå till eller som en kammarrättsdomare skrev i ett brev till mig: "Äntligen har jag förstått varför jag aldrig har förstått skatteflyktslagen." Det enda jag funnit i den rättsvetenskapliga doktrinen, som skulle kunna förklara detta tänkesätt, är att det måste vara fråga om en s.k. objektiv teleologisk metod, vilket en gång i tiden förfäktades av en tysk rättsvetare, men som aldrig vann någon förståelse bland kollegorna och som av professor Hans Thornstedt kritiserats för att vara i strid med legalitetsprincipen. Det leder bara till godtyckliga spekulationer och är egentligen endast ett skenargument för en egen värdering.

Detta är också symptomatiskt för rättspraxis. Sture Bergström och jag, som kontinuerligt har studerat rättspraxis, kom till en gemensam ståndpunkt, nämligen att det av praxis är omöjligt att förstå när och hur klausulen skall tillämpas. Vi vet egentligen bara en sak, att den inte skall tillämpas när ett visst förfarande varit känt för lagstiftningsansvariga under lång tid och ingenting har hänt från lagstiftarhåll - ett slags passivitetsansvar. Bergström hoppades på att ytterligare praxis skulle klargöra tillämp- 
ningen. För egen del tror jag att det inte är möjligt, eftersom det inte finns en begriplig metod. Då blir det godtycke och det går inte att förutse det godtyckliga. Fall efter fall dyker upp som en överraskning. Ingen visste hur det skulle gå.

Så länge man har definierat problemet med lagstiftningsluckor så att effekterna av dessa är de skattskyldigas fel har man varit kvar i det perspektivet. En av de mer komiska diskussionerna i förarbetena till skatteflyktslagen är den om det "illojala syftet" eller det "onda syftet". Här finns det en risk att bli paranoid eller att försöka finna ett moralargument, som i engelsk och amerikansk litteratur skämtsamt brukar uttryckas som att "tax reduction is evil, when it is done evilly". De illojala, onda skattskyldiga, som upptäcker luckor i lagen, skall då åtminstone skrämmas, om inte till lydnad och lojalitet, så åtminstone med en besvärande oro för att Skatteverket och domstolarna kan gå utanför lagen och kanske ändå beskatta dem och därtill påföra skattetillägg. Är detta god juridik och ett rättssystems uppgift?

Det har således visat sig att vi inte löst problemet med skattekringgående, utan bara skapat ett ytterligare problem med domstolsprocesser och enormt mycket tänkande på ett problem som inte går att lösa. Vi har inte löst problemet med skatteundvikande förfaranden. De fortsätter, eftersom det alltid går att hoppas på att Skatteverket och domstolarna inte orkar kränga rättstillämpningen på detta sätt. Vidare har vi satt legalitetsprincipen åt sidan och därmed urholkat traditionellt rättstänkande på skatteområdet. Nu sitter vi med två problem i stället för att ha löst det första ("two faults doesn't make one right").

Om det inte går att finna en bra skatteklausul, genomsynsmetod eller något annat på tillämparnivå, vad skall man göra då? Jo, kanske fundera på att lösa problemet med lagstiftningsluckor där det enligt grundlagen skall lösas - på lagstiftningsnivå.

\section{Lagstifningsperspektivet - en Tätningskommission}

Det är klart, att vi kan se den stackars lagstiftaren som ett offer och de skattskyldiga som onda, illojala skatteplanerare. Men ett annat perspektiv är faktiskt att vi genom skatt tar enskildas egendom, utan direkt vederlag, som definitionen av skatt lyder. Kan man då förvänta sig något annat än att folk ser om sitt hus. Nu menar jag inte skattebrott, dvs. att fuska gentemot fiscus, utan att det finns många som anlitar konsulter för att se om det finns något lagligt sätt som de kan minska skatten på. "A tax dollar is also a dollar" som amerikanarna brukar säga och att "tax planning is as American as apple pie".

Problemet är från detta perspektiv inte att människor utnyttjar heterogena inslag eller brister, s.k. luckor, i lagstiftningen - för det kommer de sannolikt att fortsätta med - utan problemet är att dessa luckor finns och, framförallt, att de ofta kvarstår i stället för att åtgärdas. Och vem äger det problemet? 
Svaret på frågan är uppenbart: Lagstiftningsansvariga. Bättre eller kompletterande regler behövs, om det visar sig att befintlig lagstiftning kan kringgås genom att, helt lagligt, förfara på ett annat sätt i stället för det man måhända tänkt sig. Oftast är det emellertid förfaranden som ingen ens tänkt på.

Lagstiftaren ligger alltid efter, har varit det mantra som upprepats i decennier. Ja, det är klart att läckan normalt måste ha visat sig innan man har anledning att ringa rörmokaren. Men det är en viss skillnad om rörmokaren kommer idag, i morgon eller om tio år. När det t.ex. gäller kapitalförsäkringsuppläggen informerade Skatteverket om detta i mitten av 1990-talet. Ingenting gjordes, vissa skattskyldiga anpassade sig och nu driver Skatteverket processer "en masse" i dessa fall, som kostar det allmänna och enskilda mycket tid och pengar. Endast skattejurister tjänar på detta.

Hade man i stället ändrat lagstiftningen allt eftersom bristerna i lagstiftningen upptäckts, hade dessa processer aldrig behövts. Men då hade kanske vissa skattskyldiga under viss tid lyckats undkomma en högre beskattning, kanske någon invänder. Förvisso, men med en snabb reaktion efter det att "luckan" upptäckts, begränsas skadan effektivt och de skattskyldiga får anpassa sig därefter med en gång. Det vinner alla på.

Tilltron till möjligheten att i rättstillämpningen lösa problemet, oavsett om det är fråga om genomsyn eller åberopande av skatteflyktslagen, ställer bara Skatteverket och domstolarna inför ett generande problem, nämligen att avvika från det vi kallar god juridik. Vissa faller in i beteendet, andra gör motstånd. För mig är det enkelt, eftersom jag är akademiker, att påtala det ohållbara i detta. För andra är det svårare, ett tryck från klienten, arbetsgivaren eller - $i$ synnerhet för domare - tvånget att hantera konflikten mellan ens moraliska ansvar och ens intellektuella redlighet.

Om i stället den instans som har ansvaret för lagstiftningen tar detta ansvar på allvar, dvs. riksdagen och i realiteten propositionsställaren, regeringen och Finansdepartementet, skulle vi slippa detta problem, att utsätta de skattskyldiga och olika funktionärer i rättssystemet för det beskrivna dilemmat. Jo, men vi har inte tillräckliga resurser, kan man invända med fog, för det är nog så.

Hur löser man då detta problem? Lagstiftningsmässigt är det inga problem i Sverige. Vi har en effektiv lagstiftningsprocess och en grundlag som tillåter retroaktiv lagstiftning, bara riksdagen - och därmed allmänheten - blivit informerad i förväg. Reglerna finns i 2 kap. $10 \S$ andra stycket regeringsformen. Det enda som krävs är en skrivelse från regeringen till riksdagen om att sådan lagstiftning är att vänta. Då får riksdagen - när propositionen väl skall behandlas - besluta att lagstiftningen skall gälla från dagen efter den dag en sådan skrivelse från regeringen kom in till riksdagens kansli. Och det är väl "fair play": Alla vet om vad som kommer och kan anpassa sig, och lagstiftningen ligger inom ramen för vad som förvarnats om. Det var just detta som var avsikten med undantaget från retroaktivitetsförbudet.

Hur ska man då praktiskt ordna med detta? Det kan ju inte vara så svårt att i Finansdepartementets regi tillsätta en särskild grupp som har till uppgift att, utifrån ett skatte- 
undvikandeperspektiv, dels granska föreslagen lagstiftning, dels åtgärda luckor i lagstiftning som redan är i kraft. Det bör vara en mycket kvalificerad grupp, med olika erfarenheter, och betald därefter. Det var detta jag avsåg med min debattartikel i Dagens Industri den 26 mars 2007. Då blir det genom lagstiftning - grundlagsmässigt korrekt och på ett förutsebart sätt - som man åtgärdar problemet med lagstiftningsluckor.

Det är intressant att notera att dekanus vid juridiska fakulteten vid Columbia University, skatteprofessorn David M. Schizer, kom med ett liknande förslag i New York Times den 16 april 2007. (Vi har inte haft någon kontakt med varandra, bör det tilläggas.). Artikeln har rubriken "A Few Good Lawyers" och handlar om problemet med kryphål (loopholes) i lagstiftningen. Schizer föreslår bl.a. att statsförvaltningen engagerar ett antal skattejurister med spetskompetens för att dels se till att lagstiftningsförslagen testas ordentligt från skatteundvikandesynpunkt, dels att en "rapid reaction force" inrättas. Han pekar på det viktiga i att en sådan grupp måste ha marknadsmässiga topplöner och rekryteras bland advokater/skatterådgivare och akademiker. Jag skulle till denna uppräkning vilja lägga seniordomare och lagskrivningskunniga.

Det viktigaste är inte hur denna grupp - Kommissionen mot skatteundvikande förfaranden, "Tätningskommissionen" - exakt skall vara beskaffad från ett yrkesperspektiv, utan att det helt enkelt är toppjurister på skatteområdet, men att det kan vara till fördel med olika erfarenheter. Låt oss t.ex. tänka oss två f.d. domare, två f.d. advokater/skattekonsulter, två lagskrivare och två akademiker, alla väl kända specialister på skatteområdet. En kvalificerad civilrättare bör nog också ingå. Till sin hjälp bör man också ha ett kansli. Det kan inte finnas några statsfinansiella skäl till att inte låta dessa experter - precis som enligt Schizers förslag - vara toppavlönade, om man jämför med kostnaden för alla dessa "genomsyns-" och "skatteflykts-"processer, plus skattekostnaden i alla fall där staten förlorat stora skattepengar på förfaranden som kunnat pågå $i$ åratal utan att någon åtgärdat luckorna.

På detta sätt skulle Finansdepartementet förfoga över en kvalificerad kommission, som skulle kunna sammanträda så fort en lucka upptäcks av Skatteverket eller någon annan och finnas till hands för att granska lagförslag. Anser kommissionen att nuvarande lagstiftning duger, ger man Skatteverket ett bra rättsligt underlag för hur man skall hantera problemet. Behövs ny lagstiftning skriver man ett förslag till finansministern, som kan föra det vidare till ett regeringssammanträde, så att ett lagstiftningsförslag eller, om det är akut, en skrivelse om att lagstiftning - med retroaktiv verkan - är att vänta, kan lämnas in till riksdagen. Inte för att jag är expert på hur den interna handläggning inom Regeringskansliet går till, men jag har svårt att tro att detta skulle behöva ta åratal, utan snarare vara en process som tar några veckor eller månader.

I vissa fall är det nog så, på grund av att man inte hinner utreda en fråga ordentligt, att vissa "tätningsbestämmelser" får en provisorisk karaktär, och då kan man tänka sig att ha en särskild lag - t.ex. lagen mot skatteundvikande förfaranden - där sådana 
bestämmelser förs in, till dess att man hunnit vinna ytterligare erfarenheter och utreda detaljerna på djupet.

Jag har diskuterat frågan och intresset att ingå i en sådan kommission med ett antal mycket välrenommerade erfarna domare och konsulter och samtliga har gillat idén och varit intresserade av att arbeta på detta sätt. Så det är nog inga svårigheter att få ihop en mycket kompetent kommission av denna typ, bara de politiskt ansvariga tar tag i idén.

I stället för att försöka lösa problemet från ett rättstillämpningsperspektiv, där vi endast skapat ett nytt problem, utan att ha kommit tillrätta med grundproblemet, kommer vi med detta lagstiftningsperspektiv att få en chans att lösa det, utan att skapa ett nytt. Låt vara att vissa enskilda personer kanske hinner igenom nätet fram till dess luckan täpps till, men med Tätningskommissionen ligger man i vart fall hack i häl på skatteplanerarna, utan att kränka legalitetsprincipen och sätta rättstillämparna inför dilemmat att upprätthålla en god juridisk metod eller tumma på denna och ändå beskatta.

Anders Hultqvist är jur. dr och docent i skatterätt. 